CLINICAL STUDY

\title{
Should anterior pituitary function be tested during follow-up of all patients presenting at the emergency department because of traumatic brain injury?
}

\author{
Anke W van der Eerden ${ }^{1}$, Marcel Th B Twickler ${ }^{2,6}$, Fred C G J Sweep ${ }^{3}$, Tjemme Beems ${ }^{4}$, Henk T Hendricks ${ }^{5}$, \\ Ad R M M Hermus ${ }^{2}$ and Pieter E Vos ${ }^{1}$ \\ Departments of ${ }^{1}$ Neurology, ${ }^{2}$ Endocrinology, ${ }^{3}$ Chemical Endocrinology, ${ }^{4}$ Neurosurgery and ${ }^{5}$ Rehabilitation Medicine, Radboud University Nijmegen \\ Medical Centre, Internal address 935, PO Box 9101, 6500 HB Nijmegen, The Netherlands and ${ }^{6}$ Department of Vascular Medicine, Academic Medical \\ Centre, University of Amsterdam, Amsterdam, The Netherlands \\ (Correspondence should be addressed to P E Vos; Email: p.vos@neuro.umcn.nl)
}

\begin{abstract}
Context: A wide range (15-56\%) of prevalences of anterior pituitary insufficiency are reported in patients after traumatic brain injury (TBI). However, different study populations, study designs, and diagnostic procedures were used. No data are available on emergency-department-based cohorts of TBI patients.

Objective: To assess the prevalence of pituitary dysfunction in an emergency-department-based cohort of TBI patients using strict endocrinological diagnostic criteria.

Methods: Of all the patients presenting in the emergency department with TBI over a 2-year period, 516 matched the inclusion criteria. One hundred and seven patients ( 77 with mild TBI and 30 with moderate/severe TBI) agreed to participate. They were screened for anterior pituitary insufficiency by GHRH-arginine testing, evaluation of fasting morning hormone levels (cortisol, TSH, free thyroxine, FSH, LH, and 17ß-estradiol or testosterone), and menstrual history 3-30 months after TBI. Abnormal screening results were defined as low peak GH to GHRH-arginine, or low levels of any of the end-organ hormones with low or normal pituitary hormone levels. Patients with abnormal screening results were extensively evaluated, including additional hormone provocation tests (insulin tolerance test, ACTH stimulation test, and repeated GHRH-arginine test) and assessment of free testosterone levels. Results: Screening results were abnormal in 15 of 107 patients. In a subsequent extensive endocrine evaluation, anterior pituitary dysfunction was diagnosed in only one patient (partial hypocortisolism). Conclusion: By applying strict diagnostic criteria to an emergency-department-based cohort of TBI patients, it was shown that anterior pituitary dysfunction is rare $(<1 \%)$. Routine pituitary screening in unselected patients after TBI is unlikely to be cost-effective.
\end{abstract}

European Journal of Endocrinology 162 19-28

\section{Introduction}

In Europe, the yearly incidence of traumatic brain injury (TBI) is 100-300 per 100000 persons $(1,2)$. Head trauma can cause damage to any region in the brain (3). Involvement of the posterior pituitary gland during the acute phase after severe head trauma has been acknowledged for years, but trauma-induced anterior pituitary dysfunction was considered rare (4). However, several recent studies have reported of a high frequency of anterior pituitary hormone insufficiency between 2 weeks and 1.5 years after TBI, varying from 15 to $56 \%$ of patients with moderate or severe TBI (Mod/STBI) (5-14).

Anterior pituitary hormone deficiencies are associated with cognitive impairment, depression, anxiety, fatigue, apathy, and impaired quality of life (15-17), problems that are also frequently reported by TBI patients (18). Therefore, abnormal anterior pituitary hormone levels after TBI might contribute to the problems reported by TBI patients. Additionally, hypogonadism may limit fertility, and hypocortisolism and hypothyroidism can be disabling and life-threatening $(19,20)$. Consequently, it was proposed that pituitary function should be screened in all patients after Mod or STBI, even in the absence of symptoms of hypopituitarism $(8,21,22)$.

It remains unknown whether the wide range of reported frequencies of abnormal hormone levels reflects true differences in the prevalence of pituitary dysfunction - attributable to regional differences in severity and treatment of trauma - or reflects differences in patient selection and diagnostic criteria applied to define pituitary dysfunction in the various studies. 
The objective of the present study was to assess the prevalence of anterior pituitary function in an emergency-department-based cohort of TBI patients using strict endocrinological criteria. Contrary to previous studies, all consecutive patients who had presented at the emergency department (ED) with TBI were eligible.

\section{Subjects and methods}

Since 1998, all TBI patients presenting at the ED of the Radboud University Nijmegen Medical Centre (RUNMC, a level I Dutch trauma center) are included in the Radboud University Nijmegen Brain Injury Cohort Study (RUBICS) if a neurologist and/or neurosurgeon is consulted. According to our hospital protocol, a neurologist and/or neurosurgeon is consulted at the ED in case a head trauma patient presents with i) a Glasgow Coma Scale (GCS) of 3-14, or ii) a GCS of 15 with loss of consciousness (LOC) and/or posttraumatic amnesia (PTA), or iii) a GCS of 15 without LOC and PTA, but fulfilling additional criteria: unclear or ambiguous accident history, persisting or progressive headache, nausea and vomiting, intoxication with alcohol or drugs, epileptic seizures, coagulation disorders, platelet aggregation inhibitors or oral anticoagulation use, confusion, disorientation, feeling dazed, retrograde amnesia, focal neurological deficits, age $>60$ or $<2$ years, high-energy accident, or visible trauma above the clavicles (including signs of skull (base) fracture) (23). According to the hospital admission GCS, TBI patients are classified as mild (GCS 13-15), moderate (Mod) (GCS 9-12), or severe (GCS $\leq 8)(23,24)$. In RUBICS, we register various clinical variables obtained from the ambulance or helicopter trauma physician, the ED, the intensive care unit (ICU), and the neurological and neurosurgical ward. Six and twelve months after TBI, the patients' functional status is assessed by neurological examination and Extended Glasgow Outcome Score version (25). For the present study, injury characteristics were derived from the RUBICS database. Additionally, we assessed actual body weight and length.

The ethics committee of the RUNMC approved the present study protocol. All patients gave informed consent before study entry.

\section{Selection of patients}

We reviewed RUBICS data of all the consecutive patients $(n=1425)$ presenting within $24 \mathrm{~h}$ after TBI at the ED between November 2004 and November 2006. Inclusion criteria were age between 18 and 65 years, and speaking Dutch. Exclusion criteria were known neuroendocrine disorders, previous evaluation in the pre-TBI period for neuroendocrine disturbances, glucocorticoid therapy within 3 months before study entry, current alcohol or drug abuse limiting daily functioning, other diseases substantially reducing life expectancy, inability to agree to participate (including mental retardation and dementia), obesity (body mass index $(\mathrm{BMI})>30 \mathrm{~kg} / \mathrm{m}^{2}$ ), pregnancy, and lactation.

All 516 eligible patients (451 with a mild TBI (MTBI) and 65 with Mod to severe TBI (STBI); Fig. 1) received an invitation for hormonal evaluation. If pituitary dysfunction is a consequence of TBI, it seems reasonable to assume that the risk of pituitary dysfunction is higher in patients with more severe TBI. Therefore, in case of no response to the invitation within 4 weeks, we additionally contacted all patients with Mod/STBI and a random set of patients with MTBI by phone. Ultimately, of the 516 eligible patients, 107 agreed to participate (77 with MTBI and 30 with Mod/STBI), and they were evaluated for pituitary dysfunction.

\section{Study design}

During the first visit, all patients were screened for insufficient function of the anterior pituitary gland. All patients with abnormal screening results were referred to the endocrinology department for extensive evaluation. The primary endpoint was pituitary dysfunction, which was confirmed by extensive endocrine evaluation.

\section{Screening for insufficient pituitary function}

All patients were screened by a GHRH-arginine provocation test $(100 \mu \mathrm{g}$ GHRH i.v. bolus injection, immediately followed by infusion of an arginine solution $(30 \mathrm{~g}$ in $30 \mathrm{~min}))$. Baseline $(0900 \mathrm{~h}$ in fasting state, $30 \mathrm{~min}$ after insertion of an i.v. catheter) serum levels of cortisol, TSH, free thyroxine $\left(\mathrm{fT}_{4}\right), \mathrm{FSH}, \mathrm{LH}$, and $17 \beta$-estradiol $\left(\mathrm{E}_{2}\right)$ (females) or testosterone (males) were assessed. Additionally, premenopausal females were interviewed regarding their menstrual pattern.

Abnormal screening results were defined as 1) peak GH level below $3.5 \mu \mathrm{g} / \mathrm{l}$ (GHRH-arginine test) (26); 2) level of any of the fasting $0900 \mathrm{~h}$ end-organ hormones below the reference range of our laboratory (i.e. cortisol $<0.20 \mu \mathrm{mol} / \mathrm{l}, \mathrm{fT}_{4}<8 \mathrm{pmol} / \mathrm{l}$, total testosterone $<11 \mathrm{nmol} / \mathrm{l}$ in males, $\mathrm{E}_{2}<10 \mathrm{pmol} / \mathrm{l}$ in premenopausal females - not using oral contraceptives - in the follicular phase, and $E_{2}<220 \mathrm{pmol} / \mathrm{l}$ in the luteal phase) with low or normal pituitary hormone levels (i.e. TSH $<4.0 \mathrm{mU} / \mathrm{l} ; \mathrm{LH}<8.5 \mathrm{U} / \mathrm{l}$ and FSH $<11 \mathrm{U} / \mathrm{l}$ in males; $\mathrm{LH}<16 \mathrm{U} / \mathrm{l}$ and FSH $<19 \mathrm{U} / \mathrm{l}$ in the follicular phase; $\mathrm{LH}<19 \mathrm{U} / \mathrm{l}$ and FSH $<15 \mathrm{U} / \mathrm{l}$ in the luteal phase). Low gonadotropin levels in postmenopausal women were defined as LH $<12$ U/l and FSH $<37$ U/l. Premenopausal females who met the biochemical criteria of hypogonadism were classified as having an abnormal gonadal screening result if they were amenorrheic for more than 6 months. 


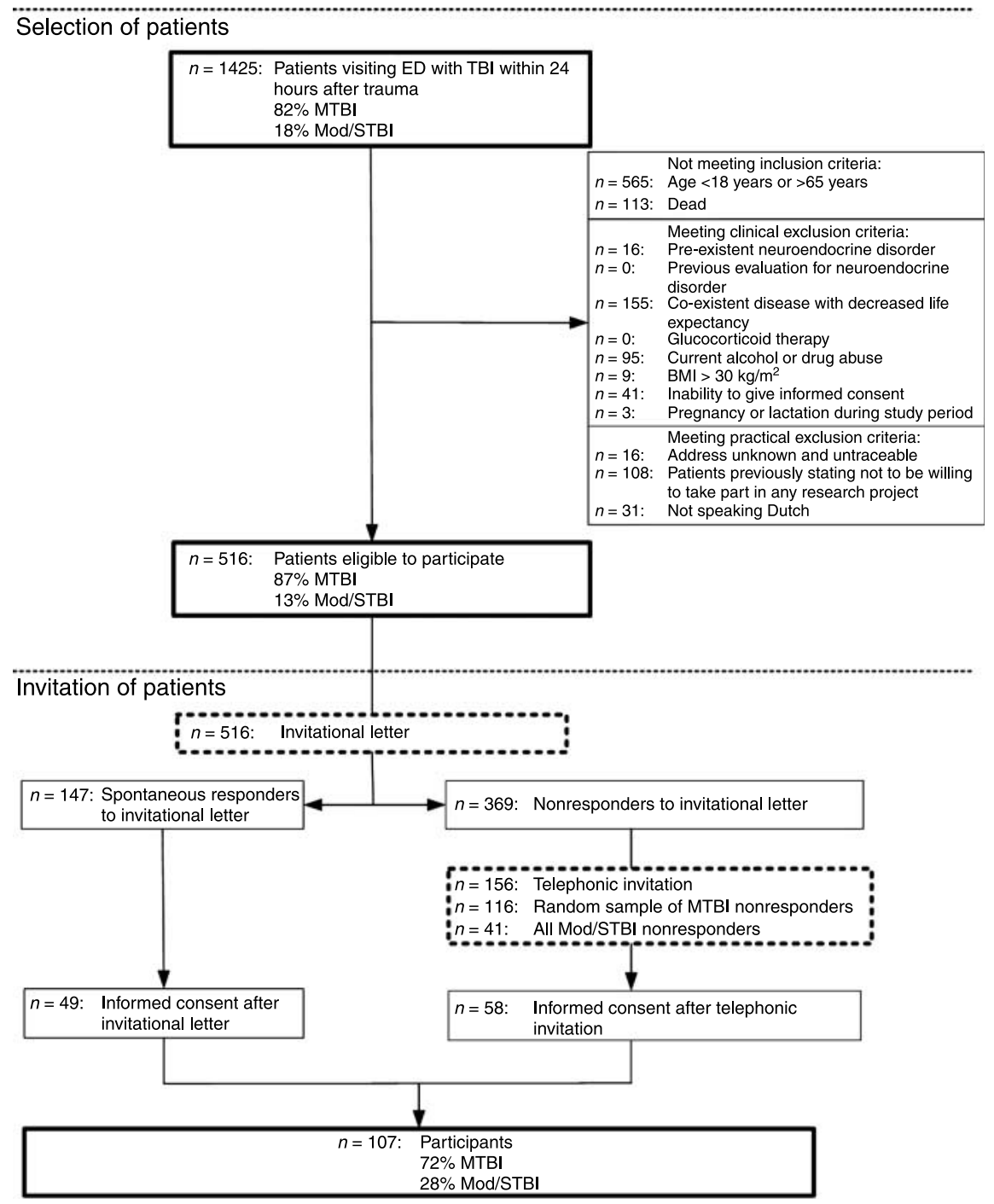

Figure 1 Patient selection flowchart.

Extensive evaluation after abnormal screening for insufficient pituitary function

Patients with one or more abnormal screening results were further evaluated by an endocrinologist within 2 months of the initial screening. Patients with abnormal somatotropic or corticotropic screening results underwent an insulin tolerance test (ITT; with lowest glucose level $<2.0 \mathrm{mmol} / \mathrm{l}$ ). In case of contraindication to ITT, in patients with abnormal somatotropic screening results, the GHRH-arginine test was repeated, whereas in patients with abnormal corticotropic screening results an ACTH stimulation test using $250 \mu \mathrm{g}$ synthetic ACTH(1-24) was performed. In males with abnormal gonadal screening results, serum-free testosterone was both directly measured and calculated (27). In males with one or both measures of free testosterone below $120 \mathrm{pmol} / \mathrm{l}$ (28), the evaluation of total and free testosterone levels was repeated.
In patients with abnormal thyrotropic screening results, the evaluation of TSH and $\mathrm{fT}_{4}$ levels was repeated.

Definitive pituitary dysfunction was diagnosed if one of the pituitary axes was disturbed at the extensive endocrinological evaluation. GHD was diagnosed in case of low peak GH to both GHRH-arginine test and ITT (i.e. maximum $\mathrm{GH}$ response $<3.5 \mu \mathrm{g} / \mathrm{l}$ to $\mathrm{GHRH}-$ arginine test and maximum $\mathrm{GH}$ response $<3.4 \mu \mathrm{g} / \mathrm{l}$ during ITT (26)), or during two GHRH-arginine tests. Hypocortisolism was defined as a low basal cortisol level with a low cortisol response during ITT (i.e. maximum cortisol response $<0.55 \mu \mathrm{mol} / \mathrm{l})$ or synthetic ACTH(1-24) (i.e. maximum cortisol response $<0.58 \mu \mathrm{mol} / \mathrm{l})$. Central hypothyroidism was defined as low $\mathrm{fT}_{4}$ with low or normal TSH at two consecutive occasions. Hypogonadism was defined as low total and free testosterone with low or normal FSH and LH at two consecutive occasions (males); persistent amenorrhea with low $\mathrm{E}_{2}$ and low or 
normal FSH and LH at two consecutive occasions (premenopausal females); or low LH and FSH at two consecutive occasions (postmenopausal females).

\section{Analytical procedures}

Serum GH was measured by RIA using an antiserum against recombinant human $\mathrm{GH}$, which was raised in a guinea pig. The same preparation was used for radioiodination. The second $(98 / 754)$ international standard for $\mathrm{GH}$ was used for the standard curve. Separation of bound and free hormone was performed by a second antibody technique. The detection limit was $0.536 \mu \mathrm{g} / \mathrm{l}$. Within and between coefficient of variations (CV) were
7.1 and $10.5 \%, 4.3$ and $8.2 \%, 5.4$ and $10.9 \%$ at levels $2.01,3.62$, and $11.79 \mu \mathrm{g} / \mathrm{l}$ respectively. Serum TSH was measured by immunoluminometric assay (ILMA) incorporated in a random access analyzer (Architect, Abbott Diagnostics). Serum $\mathrm{fT}_{4}$ was estimated by a luminescence enzyme immunoassay incorporated in a random access assay system (Vitros ECI, Ortho Clinical Diagnostics, Beerse, Belgium).

Serum testosterone was assessed by ${ }^{3} \mathrm{H}-\mathrm{RIA}$ after ether extraction of the samples, including correction for procedural losses (29). Symmetric dialysis for the measurement of the free testosterone fraction (free/total ratio) was performed as described previously (29) with the following modifications: samples were diluted $1+1$

Table 1 Characteristics of the eligible patients before study entry. Data are separately presented for participants, and for patients meeting the selection criteria of this study but not participating in the endocrine evaluation (nonparticipants).

\begin{tabular}{|c|c|c|c|c|}
\hline \multirow[b]{2}{*}{ Variable } & \multicolumn{2}{|c|}{ Participants } & \multicolumn{2}{|c|}{ Nonparticipants } \\
\hline & $\operatorname{MTBI}(n=77)^{\dagger}$ & $\operatorname{Mod} / \mathrm{STBI}(n=30)^{\dagger}$ & $\operatorname{MTBI}(n=374)$ & $\operatorname{Mod} / \mathrm{STBI}(n=35)$ \\
\hline \multicolumn{5}{|l|}{ Pre-injury } \\
\hline Age (years) & $45(22-63)^{\star}$ & $36(21-62)$ & $35(21-61)$ & $36(20-65)$ \\
\hline Male gender & $50(65 \%)$ & $20(67 \%)$ & $260(70 \%)$ & $28(80 \%)$ \\
\hline Physical comorbidity & $52(68 \%)^{*}$ & $17(57 \%)$ & $189(51 \%)$ & $14(40 \%)$ \\
\hline Prior head injury & $4(5 \%)$ & $0(0 \%)$ & $15(4 \%)$ & $1(3 \%)$ \\
\hline \multicolumn{5}{|l|}{ Peri-injury } \\
\hline Admission GCS & $15(3-15)$ & $3(3-12)$ & $15(13-15)$ & $3(3-12)$ \\
\hline \multicolumn{5}{|l|}{ Mechanism of injury } \\
\hline Traffic & $34(44 \%)$ & $19(63 \%)$ & $183(49 \%)$ & $23(66 \%)$ \\
\hline Fall & $23(30 \%)$ & $6(20 \%)$ & $91(24 \%)$ & $10(29 \%)$ \\
\hline Sports & $9(12 \%)$ & $3(10 \%)$ & $36(10 \%)$ & $1(3 \%)$ \\
\hline Other & $11(14 \%)$ & $2(7 \%)$ & $65(17 \%)$ & $1(3 \%)$ \\
\hline Hypoxia at entry in ED & $5(6 \%)$ & $7(23 \%)$ & $10(3 \%)$ & $5(14 \%)$ \\
\hline Hypotension at entry in ED & $5(6 \%)^{*}$ & $7(23 \%)$ & $4(1 \%)$ & $5(14 \%)$ \\
\hline Loss of consciousness & $44(57 \%)$ & $29(97 \%)$ & $188(50 \%)$ & $33(94 \%)$ \\
\hline \multicolumn{5}{|l|}{ Duration of PTA } \\
\hline No PTA & $38(49 \%)$ & $1(3 \%)$ & $175(47 \%)$ & $0(0 \%)$ \\
\hline PTA 1-30 min & $30(39 \%)$ & $0(0 \%)$ & $142(38 \%)$ & $0(0 \%)$ \\
\hline $\mathrm{PTA}>30 \mathrm{~min}$ & $9(12 \%)$ & $29(97 \%)$ & $57(15 \%)$ & $35(100 \%)$ \\
\hline Headache on admission & $23(31 \%)$ & $1(14 \%)$ & $106(29 \%)$ & $0(0 \%)$ \\
\hline Headache not applicable ${ }^{a}$ & 2 & 23 & 3 & 23 \\
\hline Nausea or vomiting & $10(13 \%)$ & $0(0 \%)$ & $63(17 \%)$ & $0(0 \%)$ \\
\hline \multicolumn{5}{|l|}{ CT characteristics } \\
\hline No CT made & $19(25 \%)$ & $0(0 \%)$ & $77(21 \%)$ & $0(0 \%)$ \\
\hline No traumatic abnormalities & $41(53 \%)$ & $1(3 \%)$ & $233(62 \%)$ & $4(11 \%)$ \\
\hline Traumatic abnormalities & $17(22 \%)$ & $29(97 \%)$ & $64(17 \%)$ & $31(89 \%)$ \\
\hline Additional extracranial injuries & $59(77 \%)^{\dagger}$ & $25(83 \%)$ & $181(48 \%)$ & $25(71 \%)$ \\
\hline ISS & $9(2-41)$ & $35(10-62)^{*}$ & $6(2-29)$ & $20(9-50)$ \\
\hline Hospitalization & $42(55 \%)$ & $30(100 \%)$ & $214(57 \%)$ & $35(100 \%)$ \\
\hline ICU & $11(14 \%)$ & $27(90 \%)$ & $22(6 \%)$ & $29(83 \%)$ \\
\hline Other ward & $31(40 \%)$ & $3(10 \%)$ & $192(51 \%)$ & $6(17 \%)$ \\
\hline Cranial surgery performed & $1(1 \%)$ & $3(10 \%)$ & $5(1 \%)$ & $1(3 \%)$ \\
\hline \multicolumn{5}{|l|}{ Post-injury } \\
\hline $\begin{array}{l}\text { Interval between TBI and endocrine } \\
\text { evaluation (months) }\end{array}$ & $13(5-29)^{*}$ & $14(5-28)$ & $18(7-29)$ & $19(6-32)$ \\
\hline GOS-E 3-9 months after TBI & $7(4-8)$ & $6(3-8)$ & $7(5-8)$ & $6(3-8)$ \\
\hline GOS-E 9-15 months after TBI & $8(5-8)$ & $7(3-8)$ & $8(6-8)$ & $6(3-8)$ \\
\hline BMI $\left(\mathrm{kg} / \mathrm{m}^{2}\right)$ & $25(19-30)$ & $24(21-29)$ & - & - \\
\hline
\end{tabular}

Data are shown as number (percentage) or as median (5-95th percentile). BMI, body mass index; GCS, Glasgow Coma Scale score; GOS-E, Extended Glasgow Outcome Scale Score version (range 1-8, higher score refers to a better functional outcome); ICU, intensive care unit; ISS, injury severity scale score (range $\mathbf{0 - 7 5}$, lower score refers to lower severity of injury to various body regions) (22); MTBI, mild traumatic brain injury; Mod/STBI, moderate to severe traumatic brain injury; $n$, number of patients; PTA, posttraumatic amnesia. ${ }^{\star} P<0.01$ for the difference between participants and nonparticipants with a similar severity of $\mathrm{TBI} ;{ }^{\dagger} P<0.001$.

${ }^{a}$ Headache on admission only applicable for patients without loss of consciousness or with loss of consciousness for $<30$ min. 
with HEPES buffer prior to dialysis. Aliquots, $180 \mu \mathrm{l}$, were taken to pipette on both sides of the membrane, and the dialysis time was $2.5 \mathrm{~h}$. As a calibrator, we used pooled serum that had been spiked with $100 \mathrm{nmol} / \mathrm{l}$ testosterone, in which the free testosterone fraction had been assessed by equilibrium dialysis with total testosterone assessment. The within-assay $\mathrm{CV}$ was $5.4 \%(n=45)$, and the between-assay CV (of duplicate means) were 4.6 and $6.4 \%$ at mean percent free testosterone levels 1.12 and $1.01 \%$ respectively $(n=6)$. We calculated a free testosterone index from total testosterone and sex hormone binding globulin (SHBG) concentrations using estimates based on the algorithm we recently developed to evaluate equilibrium constants of testosterone and SHBG or albumin from serum-free testosterone measurements by a near-reference method, i.e. symmetric dialysis (27). This free testosterone index perfectly matches with the free testosterone concentrations measured by symmetric dialysis. SHBG was measured by a commercial ILMA performed on an Abbott Architect Immunoanalyzer (Abbott).

$\mathrm{E}_{2}$ was evaluated after ether extraction of $0.5 \mathrm{ml}$ serum to which recovery tracer was added, followed by chromatography on Sephadex LH20 columns by RIA (30).

Serum FSH and LH were determined with fluorescenceimmunoenzymaticassay (Abbott Diagnostics) using a random access analyzer (Type AxSYM; Abbott).

Serum total cortisol was measured by luminescence immunoassay on an Architect random access analyzer (Abbott).

\section{Statistical analyses}

Data were analyzed using SPSS software version 12.0. To evaluate whether the participants with MTBI were a representative sample of all the eligible patients with MTBI and whether the participants with Mod/STBI were representative for all the patients with Mod/STBI, participants, and nonparticipants (i.e. patients meeting the study criteria but not participating in the hormonal evaluations) were compared using the two-sample $t$-test in case of continuous measures, Wilcoxon-MannWhitney test for ordinal data, and $\chi^{2}$ test for frequency data. To correct for multiple testings, a $P$ value $<0.01$ was considered significant. Prevalences of pituitary dysfunction were described as percentages with exact 95\% confidence intervals (CIs) of prevalences.

\section{Results}

\section{Patient characteristics}

Compared with nonparticipants with MTBI, participants with MTBI had more prognostically unfavorable characteristics (i.e. a higher age, more comorbidity, and more extracranial injury), and a shorter interval between TBI and endocrine evaluation (median 13 vs 18 months). Participants with Mod/STBI had higher injury severity scores (31) as compared with nonparticipants with Mod/STBI. No relation was found between the severity of TBI and interval between TBI and endocrine evaluation (Table 1).

\section{Endocrine evaluation}

While screening the 107 patients for insufficient pituitary function, 15 patients $(14.0 \%)$ with abnormal results were identified. The results of this initial screening were abnormal for the following axes: GH-insulin-like growth factor 1 (IGF1; $n=1)$, pituitary-gonadal ( $n=7$ males), pituitary-adrenal $(n=6)$, and pituitary-thyroid $(n=1)$ axes (Table 2$)$.

In a subsequent extensive endocrine evaluation of all the 15 patients with initial abnormal screening results, 14 patients were found to have hormone levels within the reference levels of our laboratory (Table 2).

Table 2 Results of extensive endocrine evaluation in patients with abnormal hormonal screening results.

\begin{tabular}{|c|c|c|c|c|}
\hline Sex & Age (years) & Severity of TBI & Screening results & Results of extensive endocrine evaluation \\
\hline $\mathrm{F}$ & 31 & MTBI & $\begin{array}{l}\text { TSH } 1.28 \mathrm{mU} / \mathrm{l} ; \mathrm{fT}_{4} \\
\quad 7.9 \mathrm{pmol} / \mathrm{l}\end{array}$ & Follow-up thyroid: TSH $1.69 \mathrm{mU} / \mathrm{l} ; \mathrm{fT}_{4} 8.4 \mathrm{pmol} / \mathrm{l}$ \\
\hline $\mathrm{F}$ & 53 & MTBI & Cort $0.15 \mu \mathrm{mol} / \mathrm{l}$ & ITT: peak cort $0.50 \mu \mathrm{mol} / \mathrm{l}$, peak ACTH $62.2 \mathrm{pmol} / \mathrm{I}$ \\
\hline $\mathrm{F}$ & 39 & ModTBI & Cort $0.14 \mu \mathrm{mol} / \mathrm{l}$ & ITT: peak cort $0.65 \mu \mathrm{mol} / \mathrm{l}$, peak ACTH $39.2 \mathrm{pmol} / \mathrm{I}$ \\
\hline M & 34 & MTBI & Cort $0.18 \mu \mathrm{mol} / \mathrm{l}$ & ITT: peak cort $0.57 \mu \mathrm{mol} / \mathrm{l}$, peak ACTH $41.2 \mathrm{pmol} / \mathrm{I}$ \\
\hline M & 46 & MTBI & Cort $0.19 \mu \mathrm{mol} / \mathrm{l}$ & ITT: peak cort $0.59 \mu \mathrm{mol} / \mathrm{l}$, peak ACTH $36.3 \mathrm{pmol} / \mathrm{I}$ \\
\hline M & 58 & MTBI & Cort $0.15 \mu \mathrm{mol} / \mathrm{l}$ & ITT: peak cort $0.58 \mu \mathrm{mol} / \mathrm{l}$, peak ACTH $63.0 \mathrm{pmol} / \mathrm{I}$ \\
\hline M & 55 & MTBI & Cort $0.15 \mu \mathrm{mol} / \mathrm{l}$ & ITT: peak cort $0.57 \mu \mathrm{mol} / \mathrm{I}$, peak ACTH $24.2 \mathrm{pmol} / \mathrm{I}$ \\
\hline M & 33 & MTBI & $\begin{array}{l}\text { GHRH-arginine test: } \\
\text { peak } \mathrm{GH} 2.35 \mu \mathrm{g} / \mathrm{l}\end{array}$ & $\begin{array}{l}\text { ITT contraindicated (epileptic seizures) } \\
\text { GHRH-arginine test: peak GH } 3.69 \mu \mathrm{g} / \mathrm{l}\end{array}$ \\
\hline M & 36 & MTBI & Test $10.3 \mathrm{nmol} / \mathrm{l}$ & fTest $_{\mathrm{d}} 333 \mathrm{pmol} / \mathrm{l} ; \mathrm{fTest}_{\mathrm{c}} 294 \mathrm{pmol} / \mathrm{l}$ \\
\hline $\mathrm{M}$ & 59 & MTBI & Test 8.04 nmol/l & fTest $_{d} 137 \mathrm{pmol} / \mathrm{l} ;$ fTest $_{\mathrm{c}} 155 \mathrm{pmol} / \mathrm{l}$ \\
\hline M & 22 & MTBI & Test $10.6 \mathrm{nmol} / \mathrm{l}$ & fTest $_{\mathrm{d}} 257 \mathrm{pmol} / \mathrm{l} ;$ fTest $_{\mathrm{c}} 288 \mathrm{pmol} / \mathrm{l}$ \\
\hline M & 41 & MTBI & Test $9.3 \mathrm{nmol} / \mathrm{l}$ & fTest $_{d} 260 \mathrm{pmol} / / ;$ fTest $_{\mathrm{c}} 231 \mathrm{pmol} / \mathrm{l}$ \\
\hline M & 44 & STBI & Test $7.79 \mathrm{nmol} / \mathrm{l}$ & fTest $_{d} 223 \mathrm{pmol} / \mathrm{l} ;$ fTest $_{\mathrm{c}} 201 \mathrm{pmol} / \mathrm{l}$ \\
\hline M & 49 & STBI & Test $8.47 \mathrm{nmol} / \mathrm{l}$ & fTest $_{d} 187 \mathrm{pmol} / \mathrm{l} ;$ fTest $_{\mathrm{c}} 202 \mathrm{pmol} / \mathrm{l}$ \\
\hline M & 41 & STBI & Test $10.3 \mathrm{nmol} / \mathrm{l}$ & fTest $_{\mathrm{d}} 139 \mathrm{pmol} / \mathrm{l} ; \mathrm{fTest}_{\mathrm{c}} 259 \mathrm{pmol} / \mathrm{l}$ \\
\hline
\end{tabular}

Cort, cortisol; $F$, female; $\mathrm{fT}_{4}$, free thyroxine; fTest ${ }_{\mathrm{c}}$, calculated free testosterone; fTest ${ }_{\mathrm{d}}$, determined free testosterone; GHD, GH deficiency; $\mathrm{M}$, male; $\mathrm{MTBI}$, mild TBI; ModTBI, moderate TBI; STBI, severe TBI; TBI, traumatic brain injury; Test, total testosterone. 


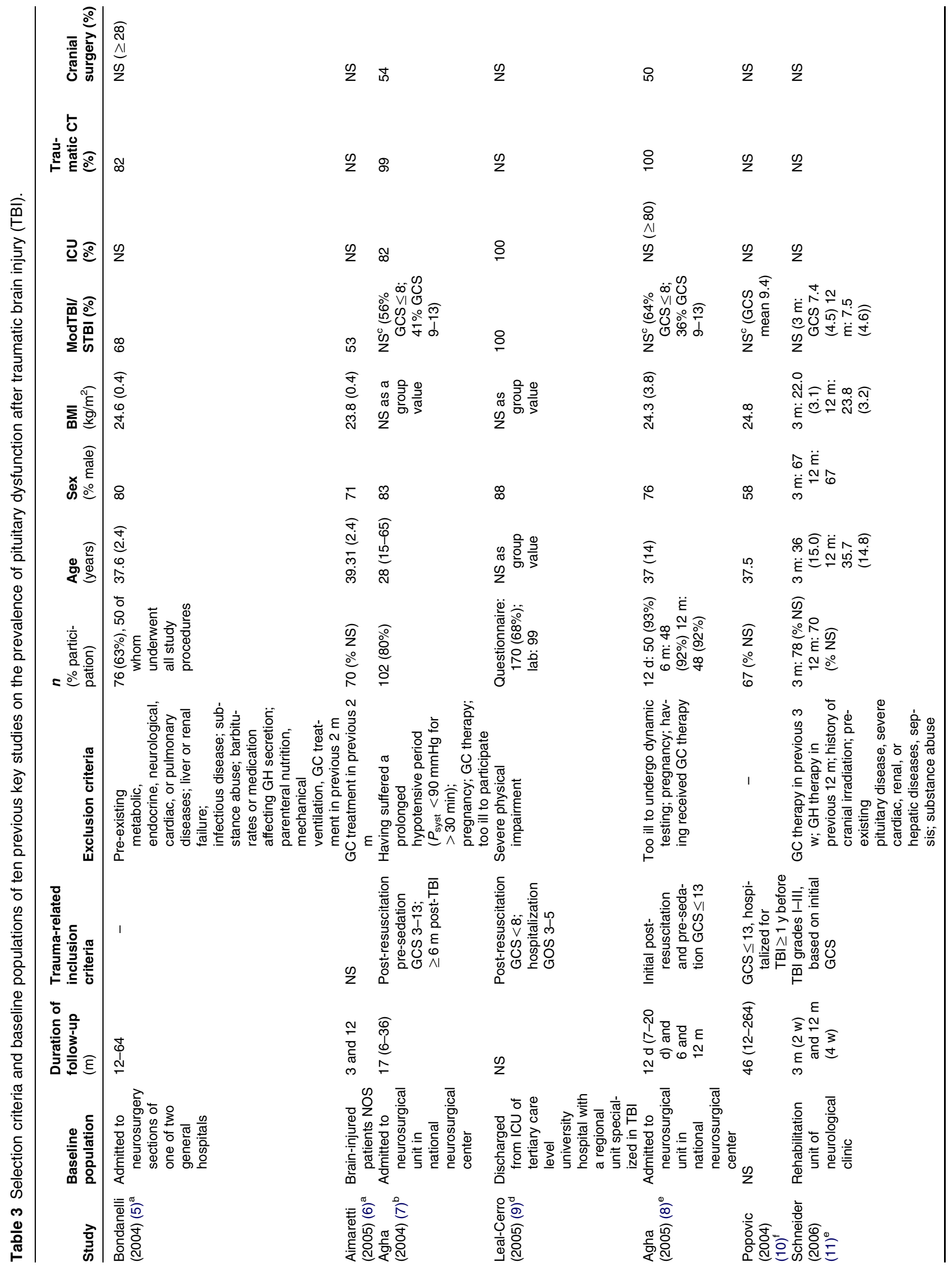




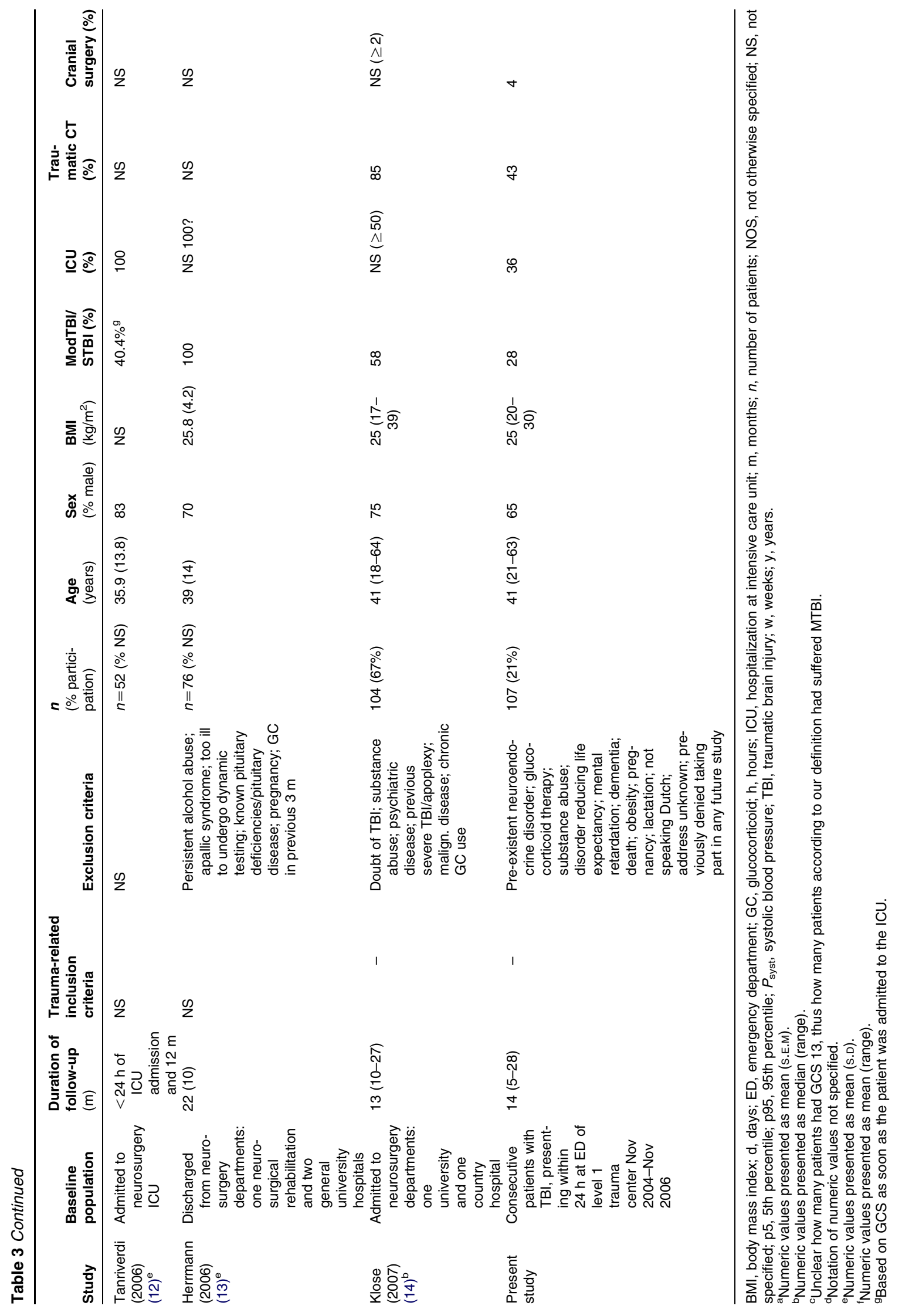

www.eje-online.org 
Partial hypocortisolism was diagnosed in one MTBI patient. Therefore, the prevalence of definitive pituitary dysfunction in our ED-based cohort of TBI patients was 0.9\% (95\% CI 0.0-5.0\%).

\section{Discussion}

In this study, $<1 \%$ of the patients had pituitary dysfunction between 3 and 30 months after presentation at the ED with TBI. In all the 30 patients with Mod/STBI participating in our study, anterior pituitary function was normal. The prevalence of hypopituitarism after TBI that we report is considerably lower than the prevalences reported by recent studies (15-56\%) (5-14). The aim of our study was to evaluate anterior pituitary function in a patient cohort representative for all the patients with TBI. Therefore, it is not surprising that our study showed a lower frequency of hypopituitarism compared with previous studies. In these previous studies $(5,7-14)$, the percentage of patients with Mod/STBI was higher (56-100\%) than that of the patients in our study. In addition to the differences in the study cohorts, the wide range of reported prevalences of hypopituitarism (varying from 15 to $56 \%$ ) may be attributed to the differences in diagnostic criteria (5-14). Furthermore, some studies included patients in whom, besides a history of TBI, alternative causes of pituitary dysfunction had not been ruled out, such as pre-existent hypopituitarism (6-10, $12,14)$, BMI above $30 \mathrm{~kg} / \mathrm{m}^{2}(5-10,12-14)$, and substance abuse $(6-10,12)$. These differences hinder the comparison of the findings of previous reports with our findings.

Table 3 summarizes the selection criteria and patient characteristics of ten previous studies on post-TBI hypopituitarism beyond the subacute phase, i.e. $>5$ months after TBI. Some authors did not unequivocally specify the population from which the study population was selected, or did not unequivocally define the selection criteria $(6,10,12,13)$. Consequently, the population in which the prevalence of pituitary dysfunction was assessed remained insufficiently defined. Contrary to our study, patients who were evaluated in all previous studies were selected from hospitalized patient populations only (at a general ward $(5,7,8,10,13,14)$, at an $\operatorname{ICU}(9,12)$, or at a rehabilitation institute (11)). Therefore, these studies included patients with more severe brain injury. In our study, all patients presenting at our ED with TBI were eligible, whether or not hospitalized thereafter. This approach increased the probability that the sample of TBI patients we evaluated was representative for a general TBI population.

Some demographic and injury characteristics were unfavorable in MTBI patients participating in our study compared with MTBI patients who did not participate. In some previous studies, no association of pituitary dysfunction with TBI severity was reported $(6,7$, 10-13), whereas others found pituitary dysfunction to be more prevalent in patients with more severe TBI $(5$, 14). In their systematic review, Schneider et al. pooled the reported prevalences in severe $(35.3 \%, 95 \%$ CI $27.3-44.2 \%)$, Mod (10.9\%, 95\% CI 5.1-21.8\%), and MTBI (16.8\%, 95\% CI 10.9-25.0\%) (22), showing that the risk of pituitary dysfunction is higher in patients with STBI than in patients with a MTBI. In order to prevent the underestimation of the prevalence of pituitary dysfunction, our study enrolment procedure implied that the largest effort was made to include patients with Mod/STBI, resulting in an overrepresentation of Mod/STBI patients. Therefore, the low prevalence of anterior pituitary dysfunction in our study cohort is unlikely to be an underestimation of the true prevalence of TBI-induced pituitary dysfunction.

Our results show that a strict differentiation should be made between definitive 'pituitary dysfunction' and 'abnormal results of hormonal screening'. Indeed, in our study, results of hormonal screening were frequently abnormal ( $14 \%$ of the patients), whereas definitive pituitary dysfunction was rare $(<1 \%$ of the patients). Supplementary Table 1 (see section on supplementary data given at the end of this article) summarizes diagnostic criteria applied in ten previous studies and the reported prevalences of pituitary dysfunction.

We and four other groups used the GHRHarginine test as the primary test to evaluate the GH-IGF1 axis $(5,6,11,13)$. Only one of those groups required confirmation by a second test, the ITT, like we did (13). For the GHRH-arginine test, previous authors used a peak $\mathrm{GH}$ of $9.0 \mu \mathrm{g} / \mathrm{l}$ as a cut-off value $(5,6,11,13)$, whereas recent clinical practice guidelines recommend $4.1 \mu \mathrm{g} / \mathrm{l}$ (26). Of our 107 patients, 13 patients $(12 \%)$ had a peak $\mathrm{GH}$ response below $9.0 \mu \mathrm{g} / \mathrm{l}$. This observation is in line with the results of previous studies defining GHD based on GHRH-arginine testing and using $9.0 \mu \mathrm{g} / \mathrm{l}$ as a cut-off value (median 9.5\%, range $8-23 \%)(5,6,11,13)$. Bondanelli et al. defined even patients with peak GH $<16.5 \mu \mathrm{g} / \mathrm{l}$ as hypopituitaristic. Indeed, they reported a very high prevalence of hypopituitarism (i.e. 54\%) (5). Such patients are unlikely to benefit from hormone substitution, and most health assurance companies will not reimburse GH substitution in these cases. Comparison of absolute hormone levels between the studies is intricate, as even after harmonization the performance of various immunoassays varies widely. For example, after harmonization, the interlaboratory $\mathrm{CV}$ of $\mathrm{GH}$ measurements is at least 7\% (32).

The diagnosis of secondary hypogonadism is challenging as no consensus exists. Most preceding studies define hypogonadism as low or normal LH and FSH levels with a low total testosterone level $(5-8,10$, $11,13)$, or less frequently a low free testosterone level $(9,12,14)$. Klose et al. were the only authors requiring 
confirmation of low testosterone levels in a second visit (14). Seven percent of our male patients had onetime low total testosterone with low or normal LH and FSH. Leal-Cerro et al. used a GnRH provocation test, but they did not specify how patients were selected for GnRH testing (9). Two previous studies defined secondary hypogonadism in females as low levels of $\mathrm{E}_{2}$, LH, and FSH $(5,12)$. Most studies, however, included additional criteria, such as the presence of menstrual disturbances $(6,9,10,14)$ or secondary amenorrhea $(7,8,11,13)$, like we did. None of our female patients was amenorrheic with low $\mathrm{E}_{2}$ and low or normal $\mathrm{LH}$ and FSH.

Aimaretti et al. defined hypocortisolism as onetime low serum cortisol or a decreased level of 24-h urinary free cortisol (6). Six percent of our patients had a low serum cortisol level at screening, but hypocortisolism was confirmed in only one patient. The prevalence of low basal serum cortisol levels in our TBI population is similar to the prevalence in an unselected sample from the general Dutch population (33). Some authors did not specify their criteria for hypocortisolism (5, 10). However, most authors diagnosed hypocortisolism with a hormone provocation test (such as $\operatorname{ITT}(7,9,13,14)$, glucagon stimulation test $(7,8)$, or short ACTH stimulation test $(7,11,14))$. Groups basing their definition of hypocortisolism on basal cortisol levels, glucagon stimulation test, or ACTH stimulation test found a relatively high prevalence of hypocortisolism (range 5-19\%) (6-8, 11, 12). Like we did, four other groups used an ITT $(7,9,13,14)$, two of which specified the selection criteria for patients to undergo ITT $(7,14)$. Three of them found a low prevalence of hypocortisolism: 1-6\% $(9,13,14)$, whereas Agha et al. found 13\% (7). Klose et al. found that $3.3 \%$ of their age- and BMI-matched controls had a cortisol response meeting their definition of hypocortisolism (14).

Hypothyroidism was mostly assessed by low $\mathrm{fT}_{4}$ and low or normal TSH according to local reference ranges $(5,6,12,13)$, or without a specification of local reference ranges $(7,8,11)$. One percent of our patients had onetime low $\mathrm{fT}_{4}$ with low or normal TSH. Klose et al. were the only authors requiring persistence of low $\mathrm{fT}_{4}$, like we did (14). Leal-Cerro et al. additionally used a TRH stimulation test (in some, but not in all patients) (9).

A limitation of this study is that because of the very low frequency of hypopituitarism, no risk factors for pituitary dysfunction could be identified. Another limitation is the use of a stimulation test of the pituitary-adrenal axis only in patients who had low basal cortisol levels. This strategy cannot unequivocally exclude relative pituitary-adrenal dysfunction. However, a low basal cortisol level does exclude absolute pituitary-adrenal dysfunction.

In conclusion, our findings show that the results of hormonal screening are abnormal in a significant proportion of patients who originally presented at the
ED with TBI, but that definite pituitary dysfunction is rare. Therefore, routine screening for hormone disturbances in unselected patients after TBI is unlikely to be cost-effective. However, screening should be advised in all patients with symptoms and signs of hypopituitarism and a history of TBI, and based on earlier reports, probably also in patients with more severe forms of TBI (e.g. those necessitating neurosurgical intervention or admission to an ICU).

\section{Supplementary data}

This is linked to the online version of the paper at http://dx.doi.org/ 10.1530/EJE-09-0436.

\section{Declaration of interest}

The authors declare that there is no conflict of interest that could be perceived as prejudicing the impartiality of the research reported.

\section{Funding}

This work was supported by NovoNordisk BV, Alphen aan de Rijn, The Netherlands, with an independent research grant. The funding source had no role in the study design, data collection, analyses, interpretation, or writing of this report. M Th B Twickler is supported by a grant of the Netherlands Organization of Research and Health (NWO-ZonMW).

\section{Author contribution statement}

P E Vos initiated the study. A W van der Eerden, P E Vos, M Th B Twickler, F Sweep, and A R M M Hermus designed the study. A W van der Eerden acquired the data. F C G J Sweep coordinated the evaluation of the serum samples. A W van der Eerden, P E Vos, M Th B Twickler, F C G J Sweep, T Beems, H T Hendricks, and A R R M Hermus analyzed and interpreted the data, and prepared the manuscript. All authors had full access to all the data and had the final responsibility for the decision to submit for publication.

\section{Acknowledgements}

We thank all the participants; Rob van den Berg and Carla Blom for laboratory work; George Borm for statistical support; Amon Heijne, Nicole van de Kamp, Jolanda Brauer, and Manon de Hingh for assisting in data acquisition and management.

\section{References}

1 Tagliaferri F, Compagnone C, Korsic M, Servadei F \& Kraus J. A systematic review of brain injury epidemiology in Europe. Acta Neurochirurgica $2006 \mathbf{1 4 8} 255-268$.

2 Hirtz D, Thurman DJ, Gwinn-Hardy K, Mohamed M, Chaudhuri AR \& Zalutsky R. How common are the "common" neurologic disorders? Neurology $200768326-337$.

3 Povlishock JT \& Katz DI. Update of neuropathology and neurological recovery after traumatic brain injury. Journal of Head Trauma Rehabilitation 200520 76-94.

4 Edwards OM \& Clark JD. Post-traumatic hypopituitarism. Six cases and a review of the literature. Medicine $1986 \mathbf{6 5} 281-290$.

5 Bondanelli M, De Marinis L, Ambrosio MR, Monesi M, Valle D, Zatelli MC, Fusco A, Bianchi A, Farneti M \& degli Uberti EC. Occurrence of pituitary dysfunction following traumatic brain injury. Journal of Neurotrauma 200421 685-696. 
6 Aimaretti G, Ambrosio MR, Di Somma C, Gasperi M, Cannavò S, Scaroni C, Fusco A, Del Monte P, De Menis E, Faustini-Fustini M, Grimaldi F, Logoluso F, Razzore P, Rovere S, Benvenga S, Degli Uberti EC, De Marinis L, Lombardi G, Mantero F, Martino E, Giordano G \& Ghigo E. Residual pituitary function after brain injury-induced hypopituitarism: a prospective 12-month study. Journal of Clinical Endocrinology and Metabolism 200590 6085-6092.

7 Agha A, Rogers B, Sherlock M, O’Kelly P, Tormey W, Philips J \& Thompson CJ. Anterior pituitary dysfunction in survivors of traumatic brain injury. Journal of Clinical Endocrinology and Metabolism 200489 4929-4936.

8 Agha A, Phillips J, O'Kelly P, Tormey W \& Thompson CJ. The natural history of post-traumatic hypopituitarism: implications for assessment and treatment. American Journal of Medicine 2005118 $1416 \mathrm{e} 1-1416 \mathrm{e} 7$.

9 Leal-Cerro A, Flores JM, Rincon M, Murillo F, Pujol M, GarciaPesquera F, Diequez C \& Casanueva FF. Prevalence of hypopituitarism and growth hormone deficiency in adults long-term after severe traumatic brain injury. Clinical Endocrinology 200562 $525-532$.

10 Popovic V, Pekic S, Pavlovic D, Maric N, Jasovic-Gasic M, Djurovic B, Medic Stojanoska M, Zivkovic V, Stojanovic M, Doknic M, Milic N, Djurovic M, Dieguez C \& Casanueva FF. Hypopituitarism as a consequence of traumatic brain injury (TBI) and its possible relation with cognitive disabilities and mental distress. Journal of Endocrinological Investigation $2004 \mathbf{2 7}$ 1048-1054.

11 Schneider HJ, Schneider M, Saller B, Petersenn S, Uhr M, Husemann B, von Rosen F \& Stalla GK. Prevalence of anterior pituitary insufficiency 3 and 12 months after traumatic brain injury. European Journal of Endocrinology 2006154 259-265.

12 Tanriverdi F, Senyurek H, Unluhizarci K, Selcuklu A, Casanueva FF \& Kelestimur F. High risk of hypopituitarism after traumatic brain injury: a prospective investigation of anterior pituitary function in the acute phase and 12 months after trauma. Journal of Clinical Endocrinology and Metabolism 200691 2105-2111.

13 Herrmann BL, Rehder J, Kahlke S, Wiedemayer H, Doerfler A, Ischebeck W, Laumer R, Forsting M, Stolke D \& Mann K. Hypopituitarism following severe traumatic brain injury. Experimental and Clinical Endocrinology and Diabetes 2006114 316-321.

14 Klose M, Juul A, Poulsgaard L, Kosteljanetz M, Brennum J \& Feldt-Rasmussen U. Prevalence and predictive factors of posttraumatic hypopituitarism. Clinical Endocrinology $2007 \mathbf{6 7}$ 193-201.

15 Van Aken MO \& Lamberts SW. Diagnosis and treatment of hypopituitarism: an update. Pituitary 20058 183-191.

16 Sternbach H. Age-associated testosterone decline in men: clinical issues for psychiatry. American Journal of Psychiatry 1998155 1310-1318.

17 Deijen JB, de Boer $\mathrm{H}$ \& van der Veen EA. Cognitive changes during growth hormone replacement in adult men. Psychoneuroendocrinology 199823 45-55.

18 Mittenberg W, Canyock EM, Condit D \& Patton C. Treatment of post-concussion syndrome following mild head injury. Journal of Clinical and Experimental Neuropsychology 200123 829-836.

19 Yamamoto T, Fukuyama J \& Fujiyoshi A. Factors associated with mortality of myxedema coma: report of eight cases and literature survey. Thyroid 19999 1167-1174.

20 Bouillon R. Acute adrenal insufficiency. Endocrinology and Metabolism Clinics of North America 200635 767-775 ix.
21 Schneider HJ, Stalla GK \& Buchfelder M. Expert meeting: hypopituitarism after traumatic brain injury and subarachnoid haemorrhage. Acta Neurochirurgica 2006148 449-456.

22 Schneider HJ, Kreitschmann-Andermahr I, Ghigo E, Stalla GK \& Agha A. Hypothalamic dysfunction following traumatic brain injury and subarachnoidal hemorrhage. A systematic review. Journal of the American Medical Association 2007298 1429-1438.

23 Vos PE, Battistin L, Birbamer G, Gerstenbrand F, Potapov A, Prevec T, Stepan ChA, Traubner P, Twijnstra A, Vecsei L, von Wild K \& European Federation of Neurological Societies. EFNS guideline on mild traumatic brain injury: report of an EFNS task force. European Journal of Neurology 20029 207-219.

24 Mild Traumatic Brain Injury Committee. Definition of mild traumatic brain injury. Journal of Head Trauma Rehabilitation 19938 86-87.

25 Wilson JT, Pettigrew LE \& Teasdale GM. Structured interviews for the Glasgow Outcome Scale and the extended Glasgow Outcome Scale: guidelines for their use. Journal of Neurotrauma 199815 573-585.

26 Molitch ME, Clemmons DR, Malozowski S, Merriam GR, Shalet SM, Vance ML, Endocrine Society's Clinical Guidelines Subcommittee, \& Stephens PA. Evaluation and treatment of adult growth hormone deficiency: an Endocrine Society Clinical Practice Guideline. Journal of Clinical Endocrinology and Metabolism 200691 1621-1634.

27 Ross HA, Meuleman EJ \& Sweep FC. A simple method for estimating equilibrium constants for serum testosterone binding resulting in an optimal free testosterone index for use in elderly men. Clinical Chemistry and Laboratory Medicine 200543 613-616.

28 Van Uytfanghe K, Stöckl D, Kaufman JM, Fiers T, Ross HA, De Leenheer AP \& Thienpont LM. Evaluation of a candidate reference measurement procedure for serum free testosterone based on ultrafiltration and isotope dilution-gas chromatography-mass spectrometry. Clinical Chemistry 200450 2101-2110.

29 Swinkels LM, van Hoof HJ, Ross HA, Smals AG \& Benraad TJ. Concentrations of salivary testosterone and plasma total, non-sexhormone-binding globulin-bound, and free testosterone in normal and hirsute women during administration of dexamethasone/synthetic corticotropin. Clinical Chemistry 199137 180-185.

30 Thomas CM, Corbey RS \& Rolland R. Assessment of unconjugated oestradiol and progesterone serum levels throughout pregnancy in normal women and in women with hyperprolactinaemia, who conceived after bromocriptine treatment. Acta Endocrinologica $197786405-414$.

31 Baker SP, O'Neill B, Haddon W Jr \& Long WB. The injury severity score: a method for describing patients with multiple injuries and evaluating emergency care. Journal of Trauma 1974 14 187-196.

32 Ross HA. Reporting growth hormone assay results in terms of one consensus recombinant standard preparation offers less than optimal reduction of between-method variation. Clinical Chemistry and Laboratory Medicine 200846 1334-1335.

33 Endert E, Ouwehand A, Fliers E, Prummel MF \& Wiersinga WM. Establishment of reference values for endocrine tests. Part IV: adrenal insufficiency. Netherlands Journal of Medicine 200563 $435-443$.

Received 16 September 2009

Accepted 24 September 2009 